\title{
SOME GENERALIZATIONS OF A HYBRID FIXED POINT THEOREM IN PARTIALLY ORDERED METRIC SPACES AND NONLINEAR FUNCTIONAL INTEGRAL EQUATIONS
}

\author{
BAPURAO C. DHAGE
}

\begin{abstract}
In this paper, the author presents some generalizations of a measure theoretic hybrid fixed point theorem of Dhage for the monotone nondecreasing mappings in a partially ordered metric space and then applies to a nonlinear functional integral equation for proving the existence as well as local ultimate attractivity of the comparable solutions defined on a unbounded interval of real line. An algorithm is constructed and it is shown that the sequence of successive approximations of the considered integral equation converges monotonically to the solution under weak partial Lipschitz and partial compactness type conditions.
\end{abstract}

Mathematics subject classification (2010): 47H07, 47H10, 34A12, 34A38.

Keywords and phrases: partially ordered metric space, partial measure of noncompactness, Dhage iteration principle, hybrid fixed point theorem, functional integral equation, attractivity of solutions.

\section{REFERENCES}

[1] J. Banas, K. Goebel, Measures of Noncompactness in Banach Space, in: Lecture Notes in Pure and Applied Mathematics, Vol. 60, Dekker, New York, 1980.

[2] J. Banas, B.C. Dhage, Global asymptotic stability of solutions of a functional integral equations, Nonlinear Anal. 69 (2008), 1945-1952.

[3] B.C. Dhage, Fixed point theorems in ordered Banach algebras and applications, PanAmer. Math. J. 9(4) (1999), 93-102.

[4] B.C. Dhage, Asymptotic stability of the solution of certain nonlinear functional integral equations via measures of noncompactness, Comm. Appl. Nonlinear Anal. 15 (2008), no. 2, 89-101.

[5] B.C. Dhage, Hybrid fixed point theory in partially ordered normed linear spaces and applications to fractional integral equations, Differ. Equ Appl. 5 (2013), 155-184.

[6] B.C. Dhage, Global attractivity results for comparable solutions of nonlinear hybrid fractional integral equations, Differ. Equ Appl. 6 (2014), 165-186.

[7] B.C. Dhage, Partially condensing mappings in ordered normed linear spaces and applications to functional integral equations, Tamkang J. Math. 45 (2014), 397-426.

[8] B.C. Dhage, Nonlinear $\mathscr{D}$-set-contraction mappings in partially ordered normed linear spaces and applications to functional hybrid integral equations, Malaya Jour. Matematik 3 (2015), 62-86.

[9] B.C. Dhage, Operator theoretic techniques in the theory of nonlinear hybrid differential equations, Nonlinear Anal. Forum 20 (2015), 15-31.

[10] B.C. Dhage, S.B. Dhage, Global attractivity and stability results for comparable solutions of nonlinear fractional integral equations, Nonlinear Studies 21 (2014), 255-268.

[11] B.C. Dhage, S.B. Dhage, Approximating solutions of nonlinear first order ordinary differential equations, GJMS Special Issue for Recent Advances in Mathematical Sciences and Applications-13, GJMS Vol. 2, No. 2, (2014), 25-35.

[12] B.C. Dhage, S.B. Dhage, Approximating positive solutions of nonlinear first order ordinary quadratic differential equations, Cogent Mathematics (2015), 2: 1023671.

[13] B.C. Dhage, S.B. Dhage, Approximating positive solutions of pbvps of nonlinear first order ordinary quadratic differential equations, Appl. Math. Lett. 46 (2015), 133-142. 
[14] B.C. Dhage, S.B. Dhage, J.R. Graef, Local attractivity and stability analysis of a nonlinear quadratic fractional integral equation, Appl. Anal. DOI: 10.1080/00036811.2015.1083984.

[15] B.C. Dhage, S.B. Dhage, D.V. Mule, Local attractivity and stability results for hybrid functional nonlinear fractional integral equations, Nonlinear Funct. Anal. \& Appl. 19, (2014), pp. 415-433.

[16] B.C. Dhage, V. Lakshmikatham, On global existence and attrctivity results for nonlinear functional integral equations, Nonlinear Analysis 72 (2010), 2219-2227.

[17] S. Heikkilä, V. Lakshmikantham, Monotone Iterative Techniques for Discontinuous Nonlinear Differential Equations, Marcel Dekker inc., New York 1994.

[18] M.A. Krasnoselskii, Topological Methods in the Theory of Nonlinear Integral Equations, Pergamon Press 1964.

[19] J.J. Nieto, R. Rodriguez-Lopez, Contractive mappings theorems in partially ordered sets and applications to ordinary differential equations, Order 22 (2005), 223-239.

[20] A.C.M. Ran, M.C.R. Reurings, A fixed point theorem in partially ordered sets and some applications to matrix equations, Proc. Amer. Math. Soc. 132 (2003), 1435-1443. 